\title{
Hanging drop cultures of human testis and testis cancer samples: a model used to investigate activin treatment effects in a preserved niche
}

\begin{abstract}
A Jørgensen *,1 , J Young ${ }^{2,3}$, J E Nielsen ${ }^{1}$, U N Joensen ${ }^{4}$, B G Toft ${ }^{5}$, E Rajpert-De Meyts ${ }^{1,6}$ and K L Loveland ${ }^{2,3,6}$
${ }^{1}$ University Department of Growth and Reproduction, Rigshospitalet, Blegdamsvej 9, 2100 Copenhagen, Denmark; ${ }^{2}$ Department of Anatomy and Developmental Biology, Monash University, Melbourne, Clayton, Victoria 3800, Australia; ${ }^{3}$ Department of Biochemistry and Molecular Biology, Monash University, Melbourne, Clayton, Victoria 3800, Australia; ${ }^{4}$ Department of Urology, Rigshospitalet, Blegdamsvej 9, 2100, Copenhagen, Denmark and ${ }^{5}$ Department of Pathology, Rigshospitalet, Blegdamsvej 9, 2100, Copenhagen, Denmark
\end{abstract}

Background: Testicular germ cell tumours of young adults, seminoma or non-seminomas, are preceded by a pre-invasive precursor, carcinoma in situ (CIS), understood to arise through differentiation arrest of embryonic germ cells. Knowledge about the malignant transformation of germ cells is currently limited by the lack of experimental models. The aim of this study was to establish an experimental tissue culture model to maintain normal and malignant germ cells within their niche and allow investigation of treatment effects.

Methods: Human testis and testis cancer specimens from orchidectomies were cultured in 'hanging drops' and effects of activin A and follistatin treatment were investigated in seminoma cultures.

Results: Testis fragments with normal spermatogenesis or CIS cells were cultured for 14 days with sustained proliferation of germ cells and CIS cells and without increased apoptosis. Seminoma cultures survived 7 days, with proliferating cells detectable during the first 5 days. Activin A treatment significantly reduced KIT transcript and protein levels in seminoma cultures, thereby demonstrating a specific treatment response.

Conclusions: Hanging drop cultures of human testis and testis cancer samples can be employed to delineate mechanisms governing growth of normal, $\mathrm{CIS}$ and tumorigenic germ cells retained within their niche.

Testicular germ cell cancer is the most common cancer in young men in the age range of $19-43$ and the incidence is generally rising (Richiardi et al, 2004; Chia et al, 2010). Testicular germ cell tumours (TGCTs) arise from precursor carcinoma in situ (CIS) cells and manifest as seminomas, which have a homogeneous immature germ cell-like phenotype, as non-seminomas, which are heterogeneous tumours comprising elements of all somatic tissues, or as combined TGCT with both histological components present
(Skakkebaek et al, 1987; Oosterhuis and Looijenga, 2005). It is currently understood that CIS cells are primordial germ cells or gonocytes that have failed to differentiate due to functional alterations in the somatic cell niche during fetal development. These arrested fetal germ cells (pre-CIS) persist within the testis during childhood and undergo an adaptation phase that includes polyploidisation and gain of chromosome 12p, which allows the CIS cells to survive in the maturing testis niche (Rajpert-De Meyts, 2006).

\footnotetext{
*Correspondence: Dr A Jørgensen; E-mail: aj@rh.regionh.dk

${ }^{6}$ These authors contributed equally to the supervision of this study.
}

Received 29 November 2013; revised 10 February 2014; accepted 4 March 2014; published online 29 April 2014 
During puberty, the CIS cells respond to changes in hormone levels by increased proliferation, and at this developmental time point the CIS cells are thought to gain the invasive capacity that facilitates tumour growth (Rajpert-De Meyts, 2006).

The mechanisms underlying the initiation and progression of testicular cancer are currently difficult to investigate since laboratory animal models, such as mice, do not develop CIS cells before TGCT. In addition, primary human germ cells are difficult to culture outside the somatic niche, and the available testicular cancer cell lines are all isolated from fully developed TGCT including a range of embryonal carcinoma lines (NTera2, 2100Ep etc.) (Andrews, 1982, 1984; Andrews et al, 1984), and the seminoma-like TCam-2 and JKT-1 cell lines (Mizuno et al, 1993; Kinugawa et al, 1998; de Jong et al, 2007, 2008). The lack of a suitable model system to investigate the early progression from CIS cells to invasive tumours has also made it difficult to determine the role of specific pathways in the pathogenesis of testicular cancer.

Several different approaches to culture human testis tissue have previously been employed, including ex vivo cultures of adult tissue and fetal testis tissue on membranes (Roulet et al, 2006; Hallmark et al, 2007; Desdoits-Lethimonier et al, 2012; Albert et al, 2013), and xenografting of fetal, pre-pubertal and adult testis tissue into nude mice (Povlsen et al, 1974; Skakkebaek et al, 1974; Geens et al, 2006; Schlatt et al, 2006; Yu et al, 2006; Wyns et al, 2007, 2008; Goossens et al, 2008; Mitchell et al, 2010). Xenografting of human testis cancer cell lines into nude mice, including JKT-1 (Li et al, 2008) and TCam-2 cells (Nettersheim et al, 2012) have also been used.

Hanging drop cultures are the widely used culture approach for both embryonic (including embryonic stem cells) and adult tissues, and have been previously successfully applied to culture intact fetal mouse testes and adult murine seminiferous tubules (Szczepny et al, 2009). This culture approach has multiple benefits, including three-dimensional tissue architecture maintenance, facilitation of efficient gas exchange and requirement for only small media and supplement volumes (Desbaillets et al, 2000; Koike et al, 2007). Importantly, these cultures are particularly effective at preserving ex vivo functional integrity and signalling activity (Desbaillets et al, 2000; Koike et al, 2007). These features led us to consider whether this approach would provide a suitable avenue through which to study the effects of specific treatments on a range of human orchidectomy specimens, from relatively normal testis tissue, to tissue containing CIS and seminoma tumours. As treatments to test with this new culture approach, we selected activin A and its highly selective and potent antagonist, follistatin (Barakat et al, 2012). Testicular germ cell tumours are considered to be sustained in vivo through a relatively frequent mutation in the KIT tyrosine kinase receptor that renders it constitutively active or through autocrine production of the KIT ligand, KITL (reviewed in Sheikine et al, 2012). Our previous results with juvenile mouse testes (Mithraprabhu et al, 2010) showed that activin exposure reduces KIT mRNA and protein levels, so we hypothesised that the highly conserved nature of gametogenesis would lead to a similar outcome in adult human testes where it is known that activin receptors are present in spermatogonia and Sertoli cells as well as in TGCT cells (Dias et al, 2008). We have also demonstrated functional activin receptors in the TCam-2 seminoma cell line, with activin A exposure resulting in higher expression of KIT and lower levels of the CIS and seminoma cell marker, AP2 $\gamma$ (Hoei-Hansen et al, 2004; Young et al, 2011).

In the context of TGCT pathogenesis, a major advantage of the hanging drop culture approach is its capacity to sustain both normal and pre-invasive germ cells within their niche, composed of the supporting Sertoli, peritubular and Leydig cells, and additional elements such as immune cells or fibroblasts, which determine the morphology and paracrine milieu of the tumour. In addition, the smaller tissue samples and media/supplement volumes required to analyse the outcomes of multiple experimental conditions make this a particularly appropriate approach given the limited size of pathological human tissue samples available for research. Ultimately, this experimental approach would be expected to support investigations on the malignant progression from CIS cell to TGCT. In this study we aimed to determine the capacity of the hanging drop culture approach to support cellular functions within human testis and testis cancer samples. Specimens containing normal testis tissue with complete spermatogenesis, CIS tubules and seminoma tumours were independently assessed. We demonstrate that cultures of normal testis tissue and CIS can be maintained for up to 14 days without signs of increased apoptosis, while the organisation of the seminiferous epithelium is preserved and germ cells continued proliferation. Cultures of seminoma samples can be maintained for up to 7 days, with histology indicating that samples remain consistent with expected tumour morphology and that proliferating seminoma cells are present for at least 3 days. Finally, we show that activin A treatment of hanging drop cultures induces specific gene and protein alterations of relevance to TGCTs. These outcomes illustrate the value of this approach for investigating responses to growth factors or chemical treatments that may ultimately be applied to alter the in vivo development and growth of testicular germ cell tumours.

\section{MATERIALS AND METHODS}

Human tissue sample collection and preparation. Patients were recruited from the Andrology Clinic of the Department of Growth and Reproduction at Copenhagen University Hospital (Denmark) in accordance with the Helsinki Declaration, and following approval from the local ethics committee (permit nr. H-1-2012-007). All participants gave informed consent before orchidectomy for treatment of testicular cancer. The orchidectomy specimens were transported immediately after surgical removal to the Pathology Department and were divided into tumour and macroscopically normal areas. The majority of the tissue was assigned for diagnostic analysis, with the remainder for research. The sample portions assigned for research were placed immediately in media (see below) and transported to the laboratory. Within $2 \mathrm{~h}$ of surgical removal, the specimens were cut into $\sim 1 \mathrm{~mm}^{3}$ pieces (an average seminiferous tubule is $150 \mu \mathrm{m}$ in diameter) and placed into hanging drop cultures in media containing DMEM F12, penicillin $\left(100 \mathrm{U} \mathrm{ml}^{-1}\right)$, streptomycin $\left(100 \mathrm{mg} \mathrm{ml}^{-1}\right)$, insulin, transferrin and selenium $(\times 1)$ with either $10 \%$ fetal bovine serum (FBS) or $0.1 \%$ bovine serum albumin (BSA). In the initial phase of culture condition optimisation, several different basic media were tested, including DMEM, RPMI1640 and $M E M \alpha$, but no apparent differences in survival or tissue morphology were observed (data not shown). All cell media and supplements were from Gibco (Naerum, Denmark), except BSA (Sigma-Aldrich, Broendby, Denmark). To set-up the cultures, $30 \mu \mathrm{l}$ drops of medium were prepared on the lid of a Petri-dish (NUNC cell culture Petri-dish). Individual tissue pieces were placed into each drop, and then the dish was carefully inverted to keep the drops intact with the tissue suspended. DPBS $(10 \mathrm{ml})$ was added to the bottom of the dish to prevent dehydration. Tissues were cultured at $34{ }^{\circ} \mathrm{C}$ in $5 \% \mathrm{CO}_{2}$ for up to 14 days, with media changed every $48 \mathrm{~h}$. The experimental set-up included at least three replicates of tissue pieces cut from the same original tissue piece for each of the following: fixation, RNA purification and survival assay. When the culture period was completed, samples were collected into $4 \%$ paraformaldehyde (PFA) fixative (30 min at room temperature, $4{ }^{\circ} \mathrm{C}$ overnight) followed by paraffin embedding for histological analysis and immunohistochemistry, placed in RNAlater (Ambion, Austin, TX, USA) for RNA purification and real-time PCR analyses or set-up in a survival assay. 
Survival assay. To evaluate whether the tissue pieces contained living cells, a survival assay was used to determine total metabolic activity using the TOX-8 in vitro toxicity assay (Sigma-Aldrich), according to the manufacturer's instructions as previously described (Jørgensen et al, 2013a). In brief, tissue pieces were transferred to a 96-well dish with $90 \mu \mathrm{l}$ media and $10 \mu \mathrm{l}$ resazurin dye (Sigma-Aldrich) and incubated for $5 \mathrm{~h}$ at $34^{\circ} \mathrm{C}$ together with negative experimental controls (media + resazurin dye, without tissue) that were included on all plates. The reduction of the oxidised form of resazurin (blue) and the concomitant increase in the fluorescent intermediate (red) were then measured on an ELISA microplate reader (Tecan Sunrise, Männedorf, Switzerland) according to the manufacturer's instructions (Sigma-Aldrich).

Immunohistochemistry. Immunohistochemistry was performed as previously described (Jørgensen et al, 2012). In brief, paraffin sections were deparaffinised and rehydrated. Antigen retrieval was accomplished by microwaving the sections for $15 \mathrm{~min}$ in retrieval buffer (Table 1). Sections were then incubated with $2 \%$ nonimmune goat serum (Zymed Histostain kit, San Francisco, CA, USA) or $0.5 \%$ milk powder diluted in Tris buffered saline (TBS) to minimise cross-reactivity. Primary antibodies, dilutions and retrieval buffers are listed in Table 1 . After $16 \mathrm{~h}$ of incubation at $4{ }^{\circ} \mathrm{C}$ and $1 \mathrm{~h}$ at room temperature, the sections were incubated with biotinylated goat anti-rabbit IgG (Zymed Histostain kit) or biotinylated goat anti-mouse $\operatorname{IgG}(1: 400)$, before a peroxidaseconjugated streptavidin complex (Zymed Histostain kit) was used as a tertiary layer. Visualisation was performed with amino ethyl carbasole (AEC) (Zymed Histostain kit) yielding a deep red colour. Between incubation steps, the slides were washed with TBS. For negative controls, serial sections were processed, with the primary antibody replaced by the dilution buffer alone. None of the control slides showed any staining. Counterstaining was performed with Mayer's haematoxylin. Serial sections were used to test for expression of PLAP (signal detected in CIS and seminoma cells), KI-67, BrdU incorporation, cleaved caspase, KIT and AP2 $\gamma$. Two independent investigators evaluated all staining. All sections were investigated manually on a Nikon Microphot-FXA microscope (Tokyo, Japan) and were then scanned on a NanoZoomer 2.0 HT (Hamamatsu Photonics, Herrsching am Ammersee, Germany) and analysed using the software NDPview version 1.2.36 (Hamamatsu Photonics). Intensity of staining was classified according to an arbitrary semi-quantitative reference scale: ++ , strong staining in all cells of a given type in the sample; $++/+$, strong staining prevalent, but some weakly stained also visible; $++/-$, strong staining present but negative cells also present; $+/++/-$, heterogeneous pattern with a mixture of strongly positive, weakly stained and negative cells; $+/++$, majority of cells weakly stained, but some strong staining present; + , weak staining overall; $-/++$, strong staining in a small number of cells; $+/-$, weak staining in limited areas; $-/+$,weak staining in single cells; - , no staining.

Quantification of immunohistochemical staining. To evaluate the immunohistochemical (IHC) stainings in a more quantitative manner, the percentages of KI-67-, BrdU-, KIT- and AP2 $\gamma$-stained cells were determined by cell counting. The proliferation markers KI-67 and BrdU were expressed only in normal and malignant germ cells, with a weakly KI-67-stained Sertoli cell observed only very rarely. In normal testis samples with complete spermatogenesis, we counted only spermatogonia and spermatocytes; in samples containing CIS, we determined only the proportion of stained CIS cells. Percentage of KIT- and AP $2 \gamma$-stained cells was determined only in seminoma cultures. For all quantifications (KI-67, BrdU, KIT and AP2 $\gamma$ ), a minimum of 100 cells were evaluated by two different investigators in each of three tissue fragments per time point/treatment from each patient. Tissue pieces from at least three different patients were included for each time point/treatment. Both positive and negative cells were counted to calculate the percentage of stained cells.

Proliferation assay. A BrdU incorporation assay was used to determine the presence of proliferating germ cells just before the end of the culture period. BrdU labelling reagent (Invitrogen, Camarillo, CA, USA) was diluted 1:100 in media and tissue pieces were set up as hanging drop cultures in BrdU containing media for $3 \mathrm{~h}$. Tissue pieces were then washed twice in PBS for $5 \mathrm{~min}$ followed by fixation and paraffin embedding as described above. BrdU was visualised by immunohistochemistry using a BrdU antibody as described in the Immunohistochemistry section, and positively stained cells were considered as proliferating. In addition, proliferation was assessed by positive KI-67 staining by immunohistochemistry (see section above).

Analysis of apoptosis. Apoptosis was determined by IHC staining with the apoptosis marker cleaved caspase 3 as described above. Furthermore, apoptosis/DNA fragmentation was detected in situ in tissue culture fragments using the terminal deoxynucleotidyl transferase (TdT)-mediated dNTP nick end labelling (TUNEL) assay that was performed using a slightly modified version of the in situ Apoptosis Detection Kit (Trevigen, Gaithersburg, MD, USA). Paraffin-embedded sections were dewaxed and rehydrated. Tissue sections were incubated with proteinase $\mathrm{K}$ to increase permeability, hydrogen peroxide $(0.3 \%)$ to block endogenous peroxidase, and buffer containing TdT enzyme and brominated dNTP. The sections were then incubated with anti-BrdU antibody conjugated with biotin followed by AEC instead of DAB which was suggested in the manufacturer's protocol. Sections were counterstained by brief immersion in Mayer's haematoxylin. Positive controls were incubated with TACS nuclease for $1.5 \mathrm{~h}$ at $37^{\circ} \mathrm{C}$ to induce DNA

\begin{tabular}{|c|c|c|c|c|c|}
\hline Antibody & Species & Dilution IHC & Dilution WB & $\begin{array}{l}\text { Retrieval } \\
\text { buffer (IHC) }\end{array}$ & $\begin{array}{l}\text { Antibody supplier } \\
\text { and product number }\end{array}$ \\
\hline BrdU & Mouse & $1: 250$ & $1: 200$ & Citrate & Dako M0744 \\
\hline PLAP & Mouse & $1: 50$ & $1: 200$ & TEG & Dako M7191 \\
\hline $\mathrm{KI}-67$ & Mouse & $1: 100$ & $1: 200$ & TEG & Dako M7240 \\
\hline $\mathrm{AP} 2 \gamma$ & Mouse & $1: 40$ & $1: 200$ & Urea & Santa Cruz sc-12762 \\
\hline KIT & Rabbit & $1: 400$ & $1: 200$ & TEG & Dako A4502 \\
\hline cCaspase 3 & Rabbit & $1: 500$ & $1: 200$ & Citrate & Abcam ab2302 \\
\hline$\beta$-Actin & Mouse & - & $1: 200$ & - & Santa Cruz sc-8035 \\
\hline
\end{tabular}



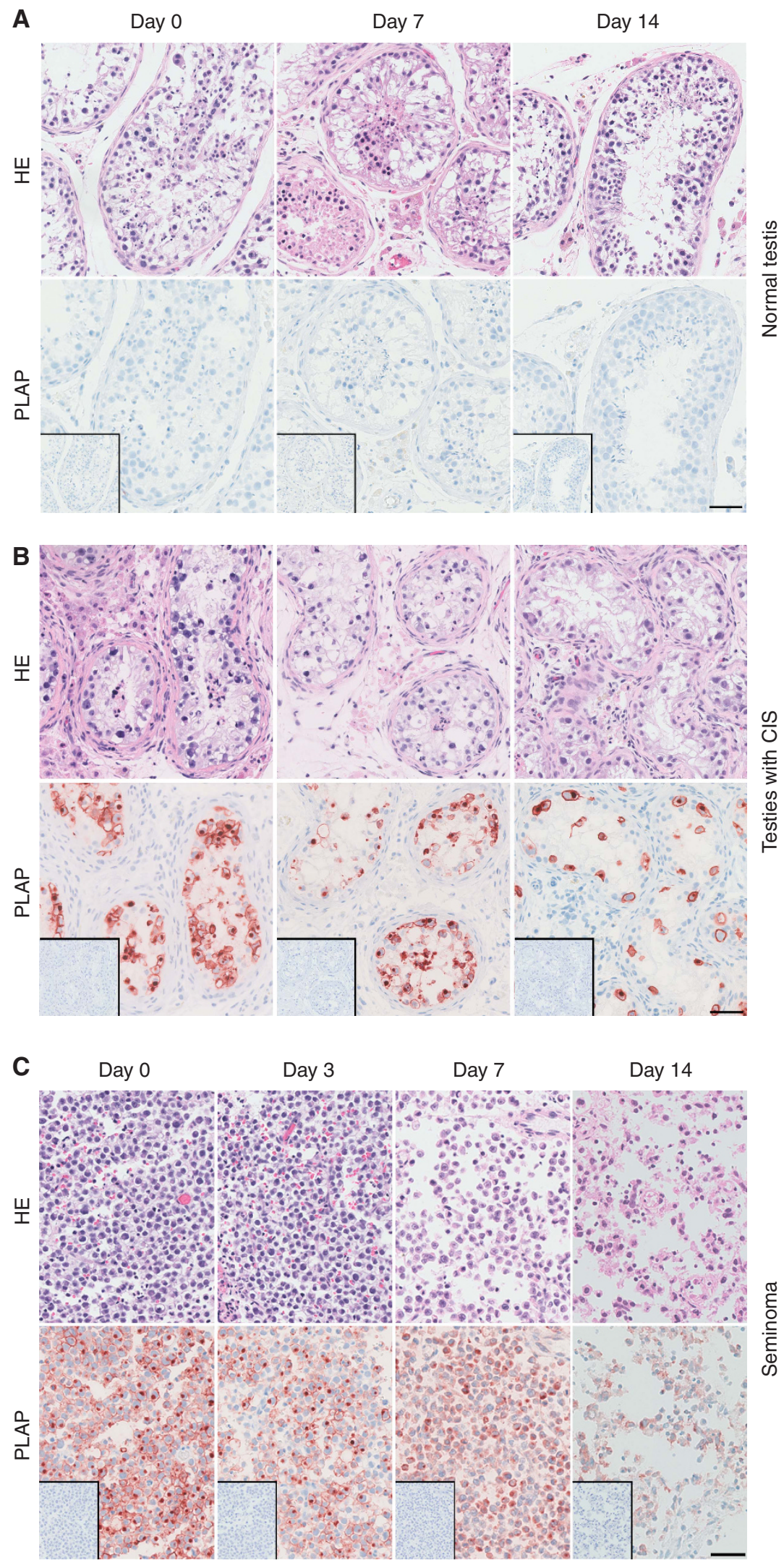

Figure 1. Morphological characterisation of tissue cultured in hanging drop cultures. (A) Human testis tissue with areas containing full spermatogenesis, termed normal testis after 0,7 and 14 days of culture in presence of $10 \%$ FBS. (B) Human testis with $\mathrm{CIS}$ after 0,7 and 14 days of culture in presence of $10 \%$ FBS. (C) Human seminoma tumour tissue after $0,3,7$ and 14 days of culture in the presence of $10 \%$ FBS. Top panel is haematoxylin and eosin (HE) staining, and bottom panel is stained with PLAP (positive in CIS and seminoma cells) and counterstained with Mayer haematoxylin. Inserts are negative control staining (no antibody). Serial sections of a representative sample are shown in each column. Tissue from 3 to 6 patients was investigated, with 3 experimental replicates per time point per patient. Scale bar corresponds to $50 \mu \mathrm{m}$. 
strand breaks. Negative controls were incubated without TdT enzyme. Sections were washed in PBS between each step.

Growth factor treatment of hanging drop cultures. To test whether hanging drop ex vivo cultures are suitable for treatment response experiments, the effects of activin A and follistatin were investigated in cultured seminoma samples. Activin A treatment (50 ng ml ${ }^{-1}$; R\&D Systems, Minneapolis, MN, USA) and follistatin (100 $\mathrm{ng} \mathrm{ml}^{-1}$; R\&D Systems) were added to media with $0.1 \%$ BSA for $48 \mathrm{~h}$ and samples were collected into PFA fixative (4\%), RNAlater for RNA purification or set-up in the survival assay (all as described above). The selected treatments and concentrations were based on results from previous experiments with activin A and follistatin in mouse seminiferous tubule cultures and the human seminoma cell line, TCam-2 (Mithraprabhu et al, 2010; Young et al, 2011).

RNA purification and quantitative RT-PCR. RNA purification and quantitative RT-PCR (qPCR) were conducted partly in Copenhagen and partly in Melbourne using different methods, but the same primers. In Melbourne, total RNA was isolated from cultured samples using the Qiagen RNeasy kit (Qiagen, Hilden, Germany). Isolated RNA was treated immediately with DNA free (Ambion) according to the manufacturer's specifications. Reverse transcription of total RNA $(500 \mathrm{ng})$ was performed in $20 \mu \mathrm{l}$ reactions with $100 \mathrm{U}$ Superscript III reverse transcriptase (Life Technologies, Naerum, Denmark) and random hexamer primers (Applied Biosystems, Foster City, CA, USA) according to the enzyme manufacturer's guidelines. For every sample, a reverse transcription reaction lacking Superscript III was included as a negative control. For $\mathrm{qPCR}, 2 \mu \mathrm{l}$ of the reverse transcription reaction was added to an $8-\mu \mathrm{l}$ reaction containing $5 \mu \mathrm{l}$ of Applied Biosystems Power SYBR-Green PCR master mix and $0.5 \mathrm{pmol}$ of each of the following forward and reverse primers. POU5F1 (NM_002701) (Fwd: 5'-CTCACCCTGGGGGTTCTATT-3', Rev: 5-CTCCAGGTTGCCTCTCACTC-3'), 18S (NR_003286.2) (Fwd: 5'-TCCCCCAACTTCTTAGAGG-3', Rev: 5'-CTTATGACCCGC ACTTACTG-3'), AP2 $\gamma$ (NM_003222) (Fwd: 5'-CCCACTGAG GTCTTCTGCTC-3', Rev: 5'-AGAGTCACATGAGCGGCTTT-3'), KIT (NM_000222) (Fwd: 5' Rev: $5^{\prime}$-AAATGCTTTCAGGTGCCATC-3'). All primers had been previously verified by melt curve analysis, amplification efficiency over serial dilutions and sequencing of amplified fragments (Young et al, 2011). Quantitative RT-PCR was performed on an Applied Biosystems $7900 \mathrm{HT}$ Analyzer using the following conditions: denaturation at $95^{\circ} \mathrm{C}$ for $10 \mathrm{~min}$, then 40 cycles of amplification at $95^{\circ} \mathrm{C}$ for $30 \mathrm{~s}, 62^{\circ} \mathrm{C}$ for $30 \mathrm{~s}$ and $72^{\circ} \mathrm{C}$ for $30 \mathrm{~s}$. Technical triplicates were performed for each individual sample, with negative controls in duplicate. Relative standard curve analysis (SDS2.0 software; Applied Biosystems) was used to quantify products generated, and all quantified results were normalised to $18 \mathrm{~S}$, and subsequently to POU5F1, transcript levels. In Copenhagen, RNA was purified using the RNAqueous-Micro Kit (Ambion) according to the manufacturer's instructions. The RNA concentration was determined using a NanoDrop ND-1000 spectrophotometer (NanoDrop Technologies, Wilmington, DE, USA). cDNA synthesis from RNA was conducted using a dT20 primer and random hexamers in $4: 1\left(0.5 \mu \mathrm{g} \mu \mathrm{l}^{-1}\right)$. Quantitative RT-PCR analysis was performed in biological triplicates and measured as technical duplicates using Stratagene Mx300P (Stratagene, La Jolla, CA, USA) with SYBR Green QPCR Master Mix (Stratagene) using the following conditions: $95^{\circ} \mathrm{C}$ for $1 \mathrm{~min}$, then 40 cycles of amplification at $95^{\circ} \mathrm{C} 30$ for $30 \mathrm{~s}, 62^{\circ} \mathrm{C}$ for $1 \mathrm{~min}, 72^{\circ} \mathrm{C}$ for $1 \mathrm{~min}$ followed by $95^{\circ} \mathrm{C} 1 \mathrm{~min}, 55^{\circ} \mathrm{C}$ for $30 \mathrm{~s}$ and $95^{\circ} \mathrm{C}$ for $30 \mathrm{~s}$. Changes in gene expression were determined with the comparative CT method using $18 S$ as an internal control and POU5F1 (encoding OCT3/4) to control for malignant germ cell content.
Western blotting. Western blotting (WB) was carried out as previously (Sonne et al, 2006; Jørgensen et al, 2013b) to verify antibody specificity. Samples included normal adult testis (NT), testis with CIS and the absence of complete spermatogenesis (CIS), and seminoma samples (SEM) (Supplementary Figure 1). Primary antibodies and dilutions are listed in Table 1 and $10 \mu \mathrm{g}$ protein was loaded in each lane. Detection of $\beta$-actin was used as a loading control based on a stable expression in normal testis tissue, tissue containing CIS and seminoma tissue (Jørgensen et al, 2013b). Secondary antibodies were HRP-conjugated rabbit anti-mouse (Dako, Glostrup, Denmark, P0260) and HRP-conjugated swine anti-rabbit (Dako, P0217), both diluted 1:1000. All antibodies appeared specific, with only one band detected at the expected size, except for the anti-AP2 $\gamma$, which detected two bands in CIS and seminoma samples (48 and $40 \mathrm{kDa}$ ), and only one faint band $(48 \mathrm{kDa})$ in the NT sample that was expected to be negative. The signals corresponding to PLAP, AP $2 \gamma$ and KIT were much more intense in seminoma samples compared with normal testis and samples with CIS (Supplementary Figure 1).

Statistical analysis. Differences in gene expression and percentage of immunopositive cells were tested by two-tailed Student's $t$-test; $P<0.05$ was considered as statistically significant.

\section{RESULTS}

Normal human testis, CIS and seminoma samples maintain normal morphology in hanging drop culture. The overall morphology of tissue with areas containing full spermatogenesis termed normal testis tissue (NT) and testis tissue with tubules containing CIS cells was maintained for up to 14 days in hanging drop tissue cultures. Staining of NT tissue with Haematoxylin \& Eosin (HE) demonstrated the presence of all germ cell types, and staining with the CIS marker PLAP confirmed that no CIS cells were present (Figure 1A). After 7-10 days of culture, a loss of more differentiated germ cells, particularly the post-meiotic spermatids, was observed in tissue from some patients, but this was not a consistent finding. In tissue containing tubules with CIS cells, staining with HE and PLAP demonstrated that the tubules contained predominantly CIS cells (positive for PLAP) and Sertoli cells (Figure 1B) and that morphology of the tissue was preserved

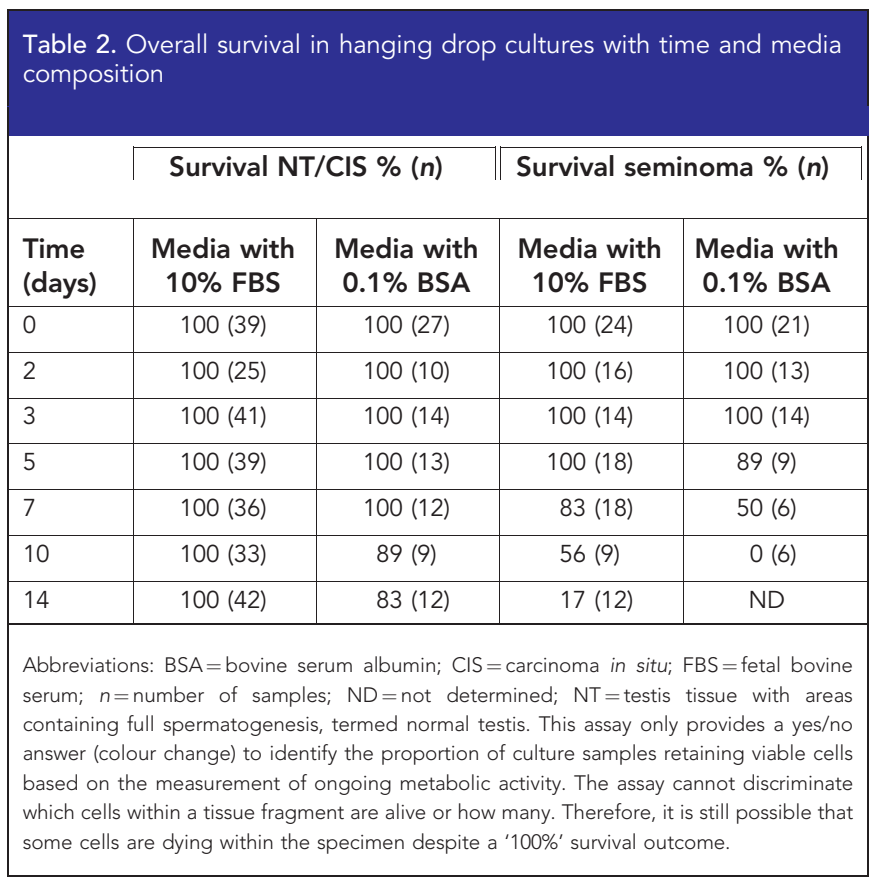


during culture for up to 14 days. In cultures of seminoma samples, the expression of embryonic markers (PLAP) was retained (Figure 1C), and the morphology of seminoma samples was relatively well preserved up to 7 days in hanging drop cultures. However, continued culturing after this time point resulted in impaired morphology with loss of seminoma cells and tissue integrity (Figure 1C).

Culture with serum supports survival of germ cells during prolonged culture. In hanging drop cultures of testis tissue containing NT and CIS, no decrease in overall survival was observed after 14 days of culture in medium containing 10\% FBS (Table 2). However, when $0.1 \%$ BSA was used instead, a decrease in survival of some samples was observed after 10-14 days of culture. This effect of media composition on survival was also evident in seminoma samples. In seminoma fragments cultured in media containing $10 \%$ FBS, a decrease in survival was observed from 7 days of culture, whereas overall cell viability loss was already evident from 5 days of culture for samples cultured in $0.1 \%$ BSA (Table 2).
Apoptosis was determined in the hanging drop cultures by investigating the presence of cleaved caspase 3 using IHC at days 0 , 7 and 14 of culture for NT and CIS samples, and at days 0,3 and 7 in seminoma samples. In general, there were very few cleaved caspase 3-positive cells and no increase with culture period was observed (Supplementary Figure 2). Apoptosis was also estimated by TUNEL assay, and the results confirmed that few apoptotic cells were present in cultured samples with no obvious change in apoptotic cell number with increasing culture period (Supplementary Figure 3). Together, these results indicate that cells in the hanging drop cultures are not dying from apoptosis, but most likely are lost via necrosis or dissociation from tissue pieces.

Germ cell proliferation in normal human testis, CIS and seminoma fragments continues up to 14 days in culture. Two measures of cell proliferation were applied in this study: IHC staining with KI-67 and a BrdU incorporation assay. To directly compare the proliferation measures, KI-67 and BrdU stainings were performed on serial sections of tissue pieces. In general, a significantly $(P<0.05)$ higher number of labelled cells was found
A Day $0 \quad$ Day 7
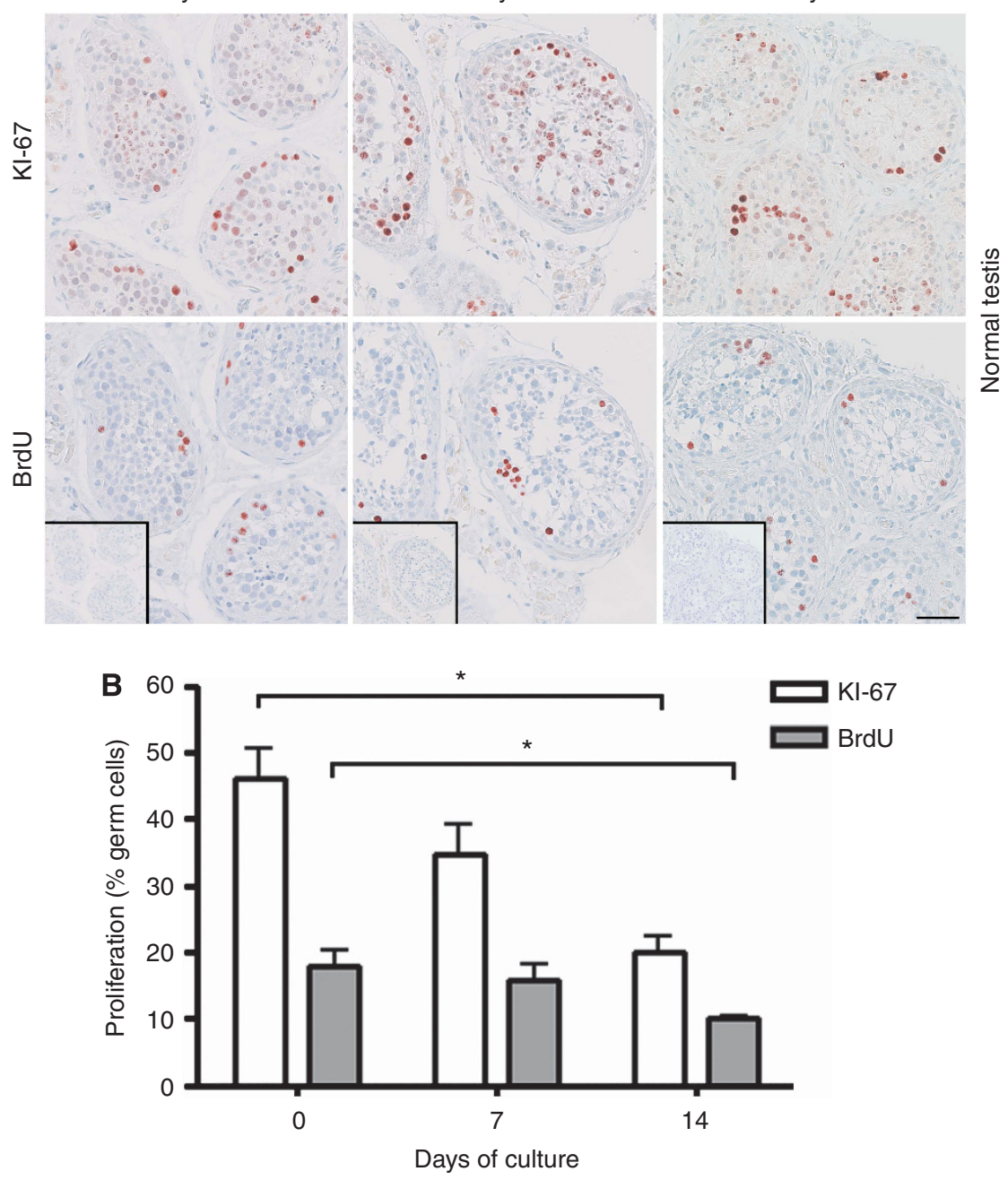

Figure 2. Cell proliferation status in cultures of human testis tissue with areas containing full spermatogenesis, termed normal testis determined by $\mathrm{KI}-67$ staining and $\mathrm{BrdU}$ incorporation after 0,7 and 14 days of culture in the presence of $10 \% \mathrm{FBS}$. (A) Top panel shows IHC staining with $\mathrm{KI}$ 67. Bottom panel shows IHC staining with BrdU. BrdU staining detects incorporated BrdU during replication for $3 \mathrm{~h}$ before tissue fixation. Inserts show negative control staining (no antibody). Serial sections of tissue counterstained with Mayer haematoxylin are shown in each column. Tissue from six patients was investigated, with three experimental replicates per time point per patient. Scale bar corresponds to $50 \mu \mathrm{m}$. (B) Quantification of proliferating germ cells (spermatogonia and spermatocytes), determined as the percentage of KI-67 staining and BrdU incorporation. Values represent mean \pm s.e.m. ${ }^{*}$ indicates significant difference $(P<0.05)$. 
by detection of KI-67 compared with BrdU (Figures 2-4). These data also indicate that BrdU incorporation, followed by antibody detection, is a more specific marker for cell proliferation than the KI-67 staining. This is expected, as BrdU is incorporated into DNA as a thymidine analogue only during $\mathrm{S}$ phase of the cell cycle in the last $3 \mathrm{~h}$ of the culture period. In contrast, KI-67 is expressed in all phases of the cell cycle, except during $G_{0} / G_{1}$ arrest (Kee et al, 2002).

In tissue containing NT and CIS cultured for 0, 7, and 14 days, proliferating cells were identified both with KI-67 and with BrdU staining at all investigated time points (Figures 2 and 3). Both measures demonstrated the presence of proliferating germ cells, indicating that the hanging drop system is supportive of their normal function. However, by 14 days of culture, a significantly $(P<0.05)$ reduced number of proliferating cells was detected compared with culture day 0 , for both NT and CIS samples. In cultures of seminoma samples, proliferating cells were detected during the first 7 days both by KI-67 staining and the BrdU assay, but with significantly $(P<0.05)$ fewer proliferating cells present after 7 days compared with both day 0 and day 3 (Figure 4).
When the culture period was extended beyond 7 days, no proliferating seminoma cells were observed (Figure 4).

Cultured seminoma tissue responds to growth factor treatment. Our previous studies have linked activin bioactivity to changes in germ cell differentiation and KIT levels (Mithraprabhu et al, 2010), and we have identified activin receptor expression in human spermatogonia, CIS and seminoma cells (Dias et al, 2008, 2009; Young et al, 2011). We therefore explored the effects of $48 \mathrm{~h}$ treatment with activin A and its antagonist, follistatin, on seminoma samples in hanging drop cultures. As there was no difference in overall survival and percentage of proliferating seminoma cells between tissue cultured in media containing $0.1 \%$ BSA and $10 \%$ FBS for 3 days, the growth factor treatment experiments were set up in media containing $0.1 \%$ BSA to avoid the presence of unknown growth factors present in the FBS, as these might influence the response to activin A and follistatin. Activin A treatment (50 $\mathrm{ng} \mathrm{ml}^{-1}$ ) resulted in a significant decrease in KIT transcript levels relative to that of the germ cell marker, POU5F1, whereas follistatin treatment $\left(100 \mathrm{ng} \mathrm{ml}^{-1}\right)$ had no
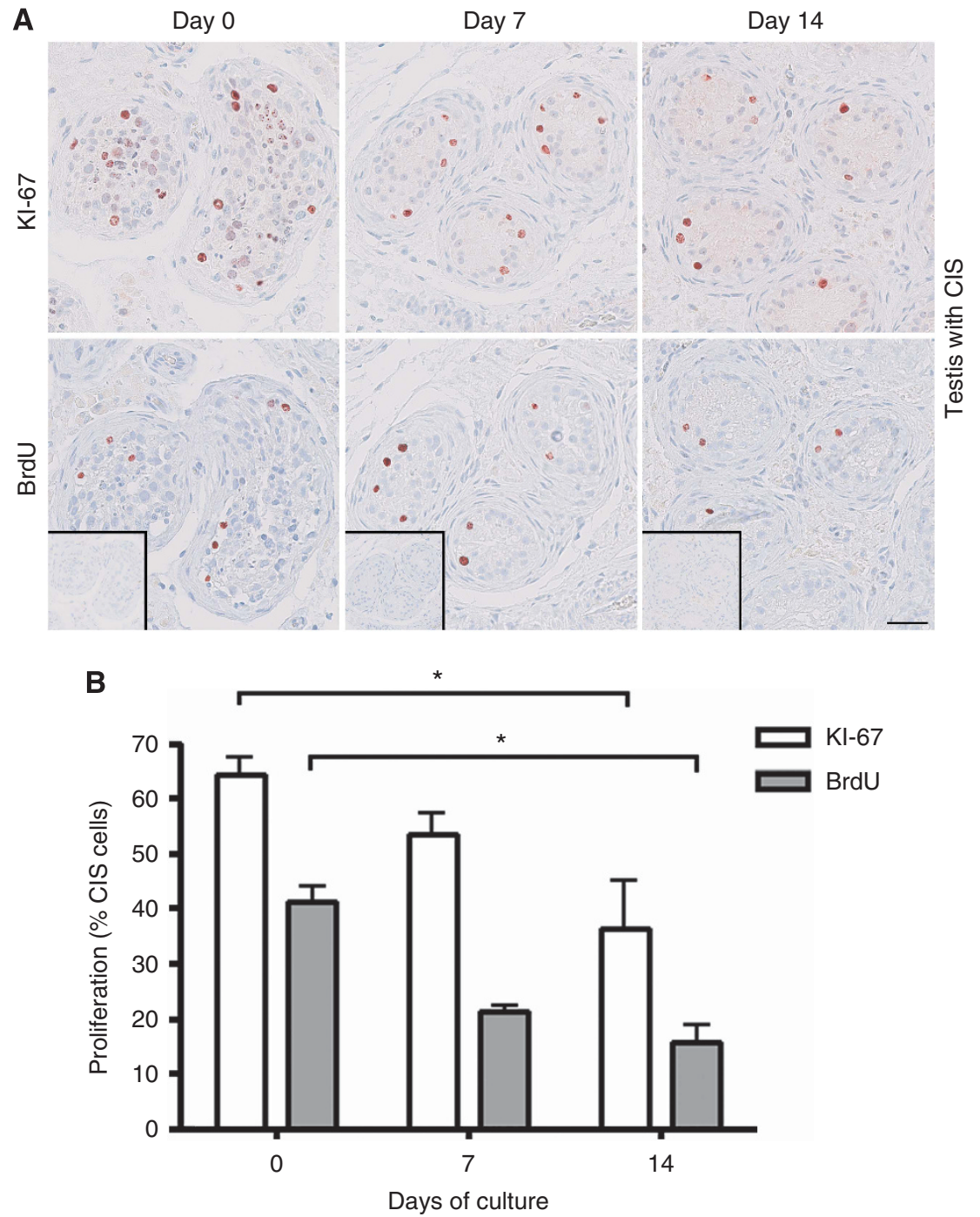

Figure 3. Cell proliferation in testis cultures containing $\mathrm{CIS}$ cells determined by $\mathrm{KI}-67$ staining and a BrdU incorporation assay after 0,7 and 14 days of culture in the presence of $10 \%$ FBS. (A) Top panel shows IHC staining with KI-67. Bottom panel shows IHC staining with BrdU. BrdU staining detects incorporated BrdU during replication for 3-h period before tissue fixation. Inserts show negative control staining (no antibody). Serial sections of tissue counterstained with Mayer haematoxylin are shown in each column. Tissue from five patients was investigated, with three experimental replicates per time point per patient. Scale bar corresponds to $50 \mu \mathrm{m}$. (B) Quantification of proliferating CIS cells (\%), determined by $\mathrm{KI}-67$ staining and BrdU incorporation. Values represent mean \pm s.e.m. ${ }^{*}$ indicates significant difference $(P<0.05)$. 

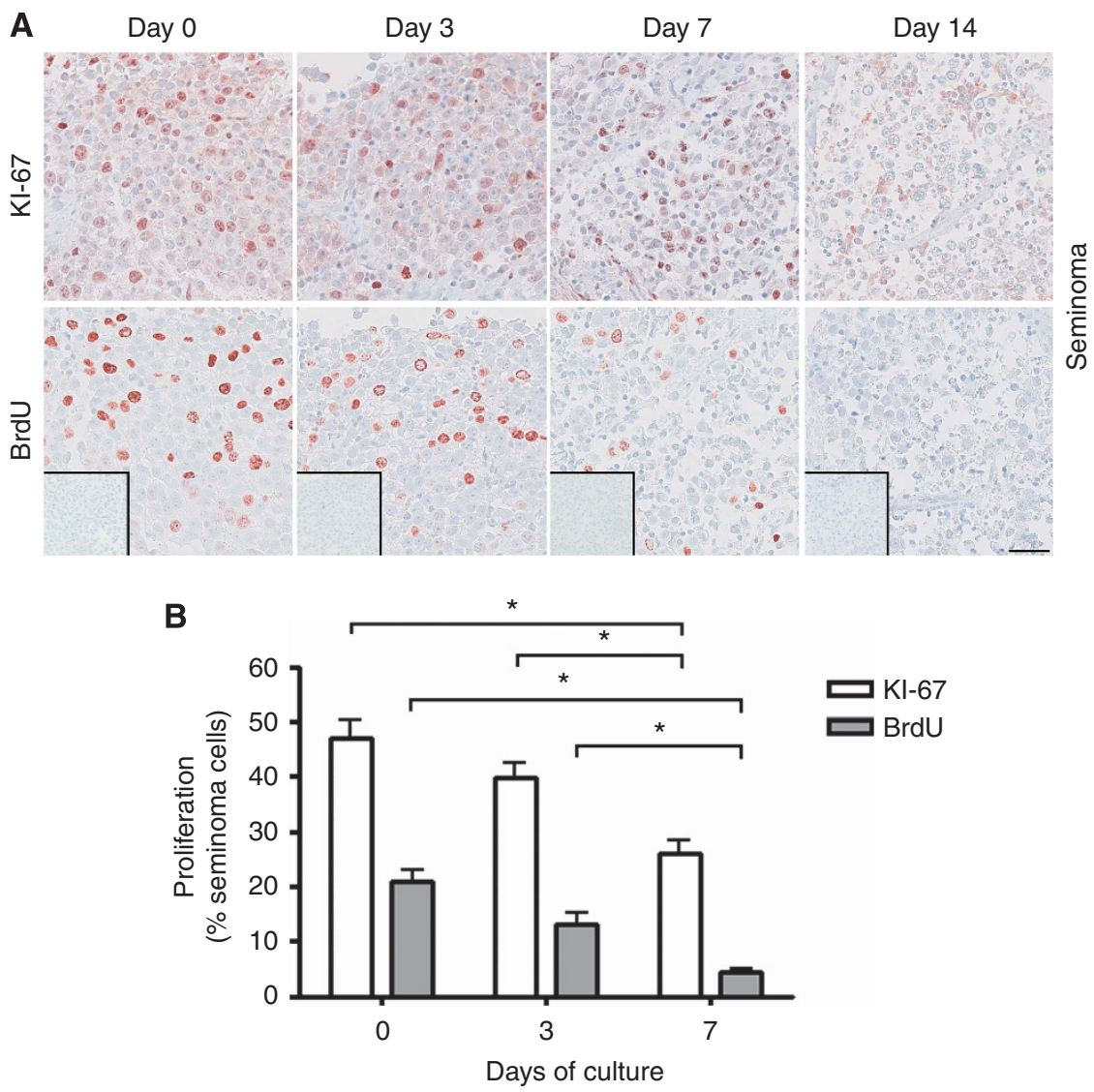

Figure 4. Proliferation of seminoma cells in culture determined by KI-67 staining and BrdU incorporation assay after 0, 3 and 7 days of culture in the presence of $10 \% \mathrm{FBS}$. (A) Top panel shows IHC staining with $\mathrm{KI}-67$. Bottom panel shows IHC staining with BrdU. BrdU staining detects incorporated BrdU during replication for 3-h period before tissue fixation. Inserts show negative control staining (no antibody). Serial sections of tissue counterstained with Mayer haematoxylin are shown in each column. Tissue from three patients was investigated, with 3 experimental replicates per time point per patient. Scale bar corresponds to $50 \mu \mathrm{m}$. (B) Quantification of proliferating seminoma cells (in percentage), determined by $\mathrm{Kl}-67$ staining and BrdU incorporation. Values represent mean \pm s.e.m. ${ }^{\star}$ indicates significant difference $(P<0.05)$.

significant impact on this (Figure 5A). Neither activin A nor follistatin treatment affected the level of $A P 2 \gamma$ transcript, indicating that the seminoma samples are responding with highly specific transcriptional changes in these culture conditions (Figure 5A). Immunohistochemical staining with KIT and AP2 $\gamma$ on corresponding seminoma samples showed the same tendency, with a lower intensity of KIT signal and proportion of KIT-positive seminoma cells in activin A-treated samples, with no difference in KIT expression after follistatin treatment (Figure $5 \mathrm{~B}$ and $\mathrm{C}$ ). In accordance with the qPCR results, no change in AP2 $\gamma$ IHC signal was detected after activin A and follistatin treatment.

\section{DISCUSSION}

This study demonstrates that human testis tissue obtained from orchidectomy specimens can be cultured short term as hanging drop tissue cultures with preservation of overall morphology and continued germ cell survival and proliferation. Furthermore, this experimental approach provides the opportunity to investigate the effects of manipulating specific signalling pathways during the malignant transformation of germ cells that are present within their somatic niche.

The main advantage of this experimental approach is that germ cells, both normal and malignant, are maintained within their normal somatic cell niche. This allows investigations of the crosstalk between germ cells and somatic cells in the context of experiments investigating effects of specific treatments, and has the potential to retain paracrine interactions that might arise from local secretion and metabolism of products. Another important advantage of the hanging drop cultures is the small amount of tissue needed. As the majority of tissue from orchidectomy specimens is used for clinical diagnosis, only small amounts are generally available for research purposes. In addition, the culture of tissue in a small volume of media also reduces the quantity of growth factors, hormones etc. needed for experiments. The hanging drop approach supports culture of testis fragments with normal spermatogenesis or CIS for up to 2 weeks with continued proliferation of germ cells, preserved tissue morphology and without increased apoptosis. Seminoma samples were supported for up to 1 week, with proliferating tumour cells present for up to 5 days. Interestingly, no increase in apoptosis (determined by cleaved caspase 3 staining and TUNEL assay) was observed in any of the cultured tissue types. However, we did observe that, with an increasing culture period, cells were dispersed from the tissue mass and could be observed as single cells within the media droplets. This was mainly observed in seminoma cultures.

During this study, we also established some important disadvantages and limitations of the hanging drop cultures. The analysis of cultured tissue relies to a large extent on immunohistochemical staining and it can be difficult to quantify outcomes specific to germ cells. There was a high degree of consistency in the results following quantification of changes in cell behaviours measured in this study, however, the results should be considered as semi-quantitative. The main limitation of this hanging drop 

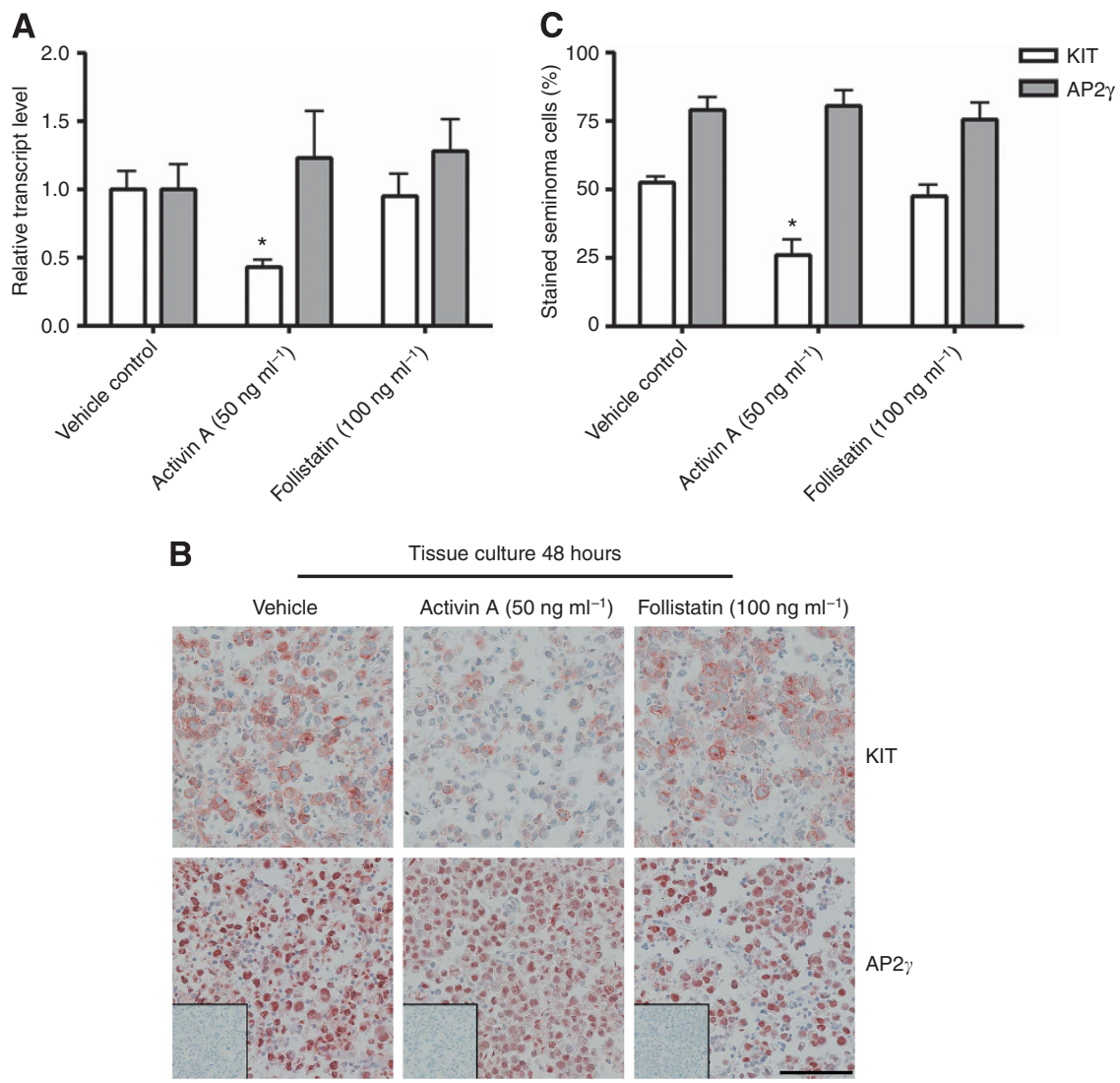

Figure 5. (A) Gene expression of KIT and AP2 $\gamma$ (TFAP2C) in seminoma cells after activin A and follistatin treatment for $48 \mathrm{~h}$ in hanging drop cultures in the presence of $0.1 \%$ BSA. Gene expression is normalised to $18 \mathrm{~S}$ (for loading) and POU5F1 (for seminoma cell content). Tissue from three patients was investigated, with three experimental replicates per treatment per patient and technical duplicates measured. Values represent mean \pm s.e.m. * indicates significant difference $(P<0.05)$. (B) Immunohistochemical staining with KIT, AP2 $\gamma$ and negative control (without antibody, shown as inserts), all counterstained with Mayer haematoxylin. Seminoma cultures treated for $48 \mathrm{~h}$ with activin A and follistatin in media containing $0.1 \%$ BSA. Serial sections are shown. Tissue from three patients was investigated, with three experimental replicates per treatment per patient. Scale bar corresponds to $100 \mu \mathrm{m}$. (C) Quantification of seminoma cells stained with KIT and AP2 $\gamma$ expressed as a percentage of total cell numbers. Values represent mean \pm s.e.m. * indicates significant difference $(P<0.05)$.

culture approach relates to the inherent heterogeneity and quality of tissue available for analysis. Among the tissue specimens from orchidectomies performed in testicular cancer patients that were included in this study, approximately one-third of the non-tumour samples turned out to consist mainly of tissue with testicular atrophy, including hyalinised tubules and large areas consisting of connective tissue and Leydig cell hyperplasia. Such undesirable tissue content is not apparent from the initial macroscopic inspection of the specimen during culture set-up and is only revealed when the overall morphology can be evaluated in sections from the fixed and paraffin-embedded samples. Also, considerable heterogeneity within the available tissue was occasionally found even among tissue pieces from the same patient, making comparisons between control and treated tissue challenging for these samples. Careful allocation of adjacent tissue samples from within a specimen to discrete groups should be employed to ensure sampling consistency is as high as possible, particularly when two different outcome measurements are compared as in the present study. However, the concern regarding tissue heterogeneity is a limitation for all tissue culture approaches in which tissue from testicular cancer patients is used. Because the simple experimental approach presented in this study uses such small pieces of tissue for individual samples, it allows for replicate measurement of treatment effects on normal and malignant adult human germ cells maintained within their somatic niche, so that conserved and distinguishing responses can be monitored from different areas of the sample tumour sample.
Several groups have previously established human testis tissue cultures (Steinberger, 1975; Kierszenbaum, 1994; Staub, 2001; Sofikitis et al, 2005), as well as CIS and seminoma tissue cultures (Lauke et al, 1991; Olie et al, 1995, 1996; Rajpert-De Meyts et al, 1998). However, the majority of these approaches had limited success and have not been systematically used. In recent years, two seminoma-derived cell lines, TCam-2 and JKT-1, have become available (Mizuno et al, 1993; Kinugawa et al, 1998) and are currently used in numerous studies. However, the general problem with the cell lines are that they are already transformed and likely contain genetic mutations that favour continued survival. Thus, the cell lines cannot be used to replicate the development and malignant progression of CIS cells.

A study by Roulet et al (2006) carefully demonstrated that normal adult human testis tissue can be cultured on membranes at the interface between air and media. This culture model was found unsuitable for preparing germ cells for therapeutic purposes, but represent a valuable tool for testing the effects of biological and chemical agents on testicular tissue (Roulet et al, 2006). Other recently applied strategies to establish an adult human testis model include xenografting of tissue pieces into nude mice, but the main aim in those studies was to determine whether this approach could be used to generate sperm from patients whose testes were to be removed, or in whom spermatogenesis was likely to be destroyed as a consequence of chemotherapy/radioactivity treatment (Geens et al, 2006; Schlatt et al, 2006). Also, TCam-2 cells were recently transplanted into seminiferous tubules of mice, resulting in the 
formation of CIS/seminoma-like cells, whereas TCam-2 cells transplanted into the flank or corpus striatum of mice resembled embryonal carcinoma cells (Nettersheim et al, 2012). This approach could also be useful to study the mechanisms that underlie the poorly understood progression of CIS into the two main TGCT subtypes. Xenografting of both normal human testis tissue and TCam-2 cells into nude mice are promising models. Unfortunately, we were not able to perform a direct experimental comparison between the hanging drop tissue culture model and xenografted tissue, due to the very small amount of available tissue and limited access to animal facilities.

An important feature when establishing a tissue culture model is to determine whether specific signalling pathways can be manipulated. Here, we investigated the effects of activin A and follistatin treatments on seminoma cultures. The observed activin A-mediated reduction in KIT expression at both gene and protein level found in cultures in this study is in accordance with the effects seen in mouse spermatogonial cultures (Mithraprabhu et al, 2010), but opposite to the response observed in the seminoma cell line TCam-2 (Young et al, 2011). Furthermore, activin A treatment of the seminoma cultures did not alter the widely used marker of CIS and seminoma cells, AP $2 \gamma$, which also contrasts previous results in TCam- 2 cells in which the $A P 2 \gamma$ transcript was significantly reduced (Young et al, 2011). We expect that the presence of somatic cells in seminoma cultures, which were absent from the TCam-2 cultures, influences the outcomes measured in these cultures. This observation provides an interesting potential to consider in future studies; in fact contrasting in vivo proliferative responses to activin A by gonocytes and Sertoli cells were previously determined in the testes of fetal mice (Mendis et al, 2011). Whether the outcome reported in this study reflects direct or indirect effects on the seminoma cells remains to be determined. The absence of an opposing response in the testis tissues following culture with follistatin suggests that these tumours already contain several mechanisms by which activin signalling is suppressed, as shown previously (Dias et al, 2009) and which can be overcome only by the presence of a highly potent exogenous signalling factor. The investigation of treatment effects in this culture system has clearly demonstrated a specific response, which indicates that the hanging drop culture approach is appropriate for delineation of the specific effects of growth factors, inhibitors and other experimental treatments which will be required to understand the basis of normal testis function and to devise new strategies to ameliorate the burden of testicular pathologies.

In conclusion, we have demonstrated that normal human testis tissue as well as tissue containing the testicular cancer precursor CIS or seminoma tumours can each be cultured in hanging drops with preservation of tissue architecture and continued proliferation of germ cells. In addition, we have shown that short-term treatment experiments result in specific functional responses by malignant germ cells. This experimental approach will allow manipulation of specific signalling pathways in normal germ cells as well as in CIS cells and thereby holds promise for the future use in studies of these testicular cancer precursor cells. The potential for modulating bioactivity of activin and other TGF $\beta$ superfamily ligands to drive tumour differentiation or death is the focus of our ongoing studies. We propose that this model system can be used to obtain mechanistic insights about the malignant transformation of CIS cells and help to understand why further progression results in the formation of seminomas in some patients and non-seminomas in others.

\section{ACKNOWLEDGEMENTS}

We wish to thank Ana Ricci Nielsen, Ina Lund, Bonnie S Håkansson, Brian Vendelbo Hansen and Betina F Nielsen for excellent technical assistance. Helpful comments and support of Professors Niels E Skakkebæk and Anders Juul are also gratefully acknowledged. This work was supported financially by the Danish Cancer Society (ERM), Familien Erichsens Mindefond and Dagmar Marshalls Fond (AJ), the Australian National Health and Medicinal Research Council grants APP100248 and APP1021156 (KLL) and the Research Fund at Rigshospitalet grant 9615.06.1.15 (JEN).

\section{REFERENCES}

Albert O, Desdoits-Lethimonier C, Lesné L, Legrand A, Guillé F, Bensalah K, Dejucq-Rainsford N, Jégou B (2013) Paracetamol, aspirin and indomethacin display endocrine disrupting properties in the adult human testis in vitro. Hum Reprod 28(7): 1890-1898.

Andrews PW (1982) Human embryonal carcinoma cells in culture do not synthesize fibronectin until they differentiate. Int J Cancer 30(5): 567-571.

Andrews PW (1984) Retinoic acid induces neuronal differentiation of a cloned human embryonal carcinoma cell line in vitro. Dev Biol 103(2): 285-293.

Andrews PW, Damjanov I, Simon D, Banting GS, Carlin C, Dracopoli NC, Føgh J (1984) Pluripotent embryonal carcinoma clones derived from the human teratocarcinoma cell line Tera-2. Differentiation in vivo and in vitro. Lab Invest 50(2): 147-162.

Chia VM, Quraishi SM, Devesa SS, Purdue MP, Cook MB, McGlynn KA (2010) International trends in the incidence of testicular cancer, 1973-2002. Cancer Epidemiol Biomarkers Prev 19(5): 1151-1159.

Barakat B, Itman C, Mendis SH, Loveland KL (2012) Activins and inhibins in mammalian testis development: new models, new insights. Mol Cell Endocrinol 359(1-2): 66-77.

de Jong J, Stoop H, Gillis AJ, Hersmus R, van Gurp RJ, van de Geijn GJ, van Drunen E, Beverloo HB, Schneider DT, Sherlock JK, Baeten J, Kitazawa S, van Zoelen EJ, van Roozendaal K, Oosterhuis JW, Looijenga LH (2008) Further characterization of the first seminoma cell line TCam-2. Genes Chromosomes Cancer 47(3): 185-196.

de Jong J, Stoop H, Gillis AJ, van Gurp RJ, van Drunen E, Beverloo HB, Lau YF, Schneider DT, Sherlock JK, Baeten J, Hatakeyama S, Ohyama C, Oosterhuis JW, Looijenga LH (2007) JKT-1 is not a human seminoma cell line. Int J Androl 30(4): 350-365.

Desbaillets I, Ziegler U, Groscurth P, Gassmann M (2000) Embryoid bodies: an in vitro model of mouse embryogenesis. Exp Physiol 85(6): 645-651.

Desdoits-Lethimonier C, Albert O, Le Bizec B, Perdu E, Zalko D, Courant F, Lesné L, Guillé F, Dejucq-Rainsford N, Jégou B (2012) Human testis steroidogenesis is inhibited by phthalates. Hum Reprod 27(5): 1451-1459.

Dias V, Meachem S, Rajpert-De Meyts E, McLachlan R, Manuelpillai U, Loveland KL (2008) Activin receptor subunits in normal and dysfunctional adult human testis. Hum Reprod 23(2): 412-420.

Dias VL, Rajpert-De Meyts E, McLachlan R, Loveland KL (2009) Analysis of activin/TGFB-signaling modulators within the normal and dysfunctional adult human testis reveals evidence of altered signaling capacity in a subset of seminomas. Reproduction 138(5): 801-811.

Geens M, De Block G, Goossens E, Frederickx V, Van Steirteghem A, Tournaye H (2006) Spermatogonial survival after grafting human testicular tissue to immunodeficient mice. Hum Reprod 21(2): 390-396.

Goossens E, Geens M, De Block G, Tournaye H (2008) Spermatogonial survival in long-term human prepubertal xenografts. Fertil Steril 90(5): 2019-2022.

Hallmark N, Walker M, McKinnell C, Mahood IK, Scott H, Bayne R, Coutts S, Anderson RA, Greig I, Morris K, Sharpe RM (2007) Effects of monobutyl and di(n-butyl) phthalate in vitro on steroidogenesis and Leydig cell aggregation in fetal testis explants from the rat: comparison with effects in vivo in the fetal rat and neonatal marmoset and in vitro in the human. Environ Health Perspect 115(3): 390-396.

Hoei-Hansen CE, Nielsen JE, Almstrup K, Sonne SB, Graem N, Skakkebaek NE, Leffers H, Rajpert-De Meyts E (2004) Transcription factor AP-2gamma is a developmentally regulated marker of testicular carcinoma in situ and germ cell tumors. Clin Cancer Res 10(24): 8521-8530.

Jørgensen A, Nielsen JE, Jensen MB, Græm N, Rajpert-De Meyts E (2012) Analysis of meiosis regulators in human gonads: a sexually dimorphic spatio-temporal expression pattern suggests involvement of DMRT1 in meiotic entry. Mol Hum Reprod 18(11): 523-534. 
Jørgensen A, Blomberg Jensen M, Nielsen JE, Juul A, Rajpert-De Meyts E (2013a) Influence of vitamin D on cisplatin sensitivity in testicular germ cell cancer-derived cell lines and in a NTera2 xenograft model. J Steroid Biochem Mol Biol 136: 238-246.

Jørgensen A, Nielsen JE, Almstrup K, Toft BG, Petersen BL, Rajpert-De Meyts E (2013b) Dysregulation of the mitosis-meiosis switch in testicular carcinoma in situ. J Pathol 229(4): 588-598.

Kee N, Sivalingam S, Boonstra R, Wojtowicz JM (2002) The utility of Ki-67 and BrdU as proliferative markers of adult neurogenesis. J Neurosci Methods 115(1): 97-105.

Kierszenbaum AL (1994) Mammalian spermatogenesis in vivo and in vitro: a partnership of spermatogenic and somatic cell lineages. Endocr Rev 15(1): 116-134.

Kinugawa K, Hyodo F, Matsuki T, Jo Y, Furukawa Y, Ueki A, Tanaka H (1998) Establishment and characterization of a new human testicular seminoma cell line, JKT-1. Int J Urol 5(3): 282-287.

Koike M, Sakaki S, Amano Y, Kurosawa H (2007) Characterization of embryoid bodies of mouse embryonic stem cells formed under various culture conditions and estimation of differentiation status of such bodies. J Biosci Bioeng 104(4): 294-299.

Lauke H, Seidl K, Hartmann M, Holstein AF (1991) Carcinoma-in-situ cells in cultured human seminiferous tubules. Int J Androl 14(1): 33-43.

Li Y, Kido T, Luo J, Fukuda M, Dobrinski I, Lau YF (2008) Intratubular transplantation as a strategy for establishing animal models of testicular germ cell tumours. Int J Exp Pathol 89: 342-349.

Mendis SH, Meachem SJ, Sarraj MA, Loveland KL (2011) Activin A balances Sertoli and germ cell proliferation in the fetal mouse testis. Biol Reprod 84(2): 379-391.

Mitchell RT, Saunders PT, Childs AJ, Cassidy-Kojima C, Anderson RA, Wallace WH, Kelnar CJ, Sharpe RM (2010) Xenografting of human fetal testis tissue: a new approach to study fetal testis development and germ cell differentiation. Hum Reprod 25(10): 2405-2414.

Mithraprabhu S, Mendis S, Meachem SJ, Tubino L, Matzuk MM, Brown CW, Loveland KL (2010) Activin bioactivity affects germ cell differentiation in the postnatal mouse testis in vivo. Biol Reprod 82(5): 980-990.

Mizuno Y, Gotoh A, Kamidono S, Kitazawa S (1993) [Establishment and characterization of a new human testicular germ cell tumor cell line (TCam-2)]. Nihon Hinyokika Gakkai Zasshi 84(7): 1211-1218.

Nettersheim D, Westernströer B, Haas N, Leinhaas A, Brüstle O, Schlatt S, Schorle H (2012) Establishment of a versatile seminoma model indicates cellular plasticity of germ cell tumor cells. Genes Chromosomes Cancer 51(7): 717-726.

Olie RA, Boersma AW, Dekker MC, Nooter K, Looijenga LH, Oosterhuis JW (1996) Apoptosis of human seminoma cells upon disruption of their microenvironment. Br J Cancer 73(9): 1031-1036.

Olie RA, Looijenga LH, Dekker MC, de Jong FH, van Dissel-Emiliani FM, de Rooij DG, van der Holt B, Oosterhuis JW (1995) Heterogeneity in the in vitro survival and proliferation of human seminoma cells. Br J Cancer 71(1): 13-17.

Oosterhuis JW, Looijenga LH (2005) Testicular germ-cell tumours in a broader perspective. Nat Rev Cancer 5(3): 210-222.

Povlsen CO, Skakkebaek NE, Rygaard J, Jensen G (1974)

Heterotransplantation of human foetal organs to the mouse mutant nude. Nature 248(445): 247-249.

Rajpert-De Meyts E (2006) Developmental model for the pathogenesis of testicular carcinoma in situ: genetic and environmental aspects. Hum Reprod Update 12(3): 303-323.

Rajpert-De Meyts E, Lauke H, Skakkebaek NE (1998) In vitro survival of human neoplastic germ cells. Adv Exp Med Biol 444: 59-65.
Richiardi L, Bellocco R, Adami HO, Torrång A, Barlow L, Hakulinen T, Rahu M, Stengrevics A, Storm H, Tretli S, Kurtinaitis J, Tyczynski JE, Akre O (2004) Testicular cancer incidence in eight northern European countries: secular and recent trends. Cancer Epidemiol Biomarkers Prev 13(12): 2157-2166.

Roulet V, Denis H, Staub C, Le Tortorec A, Delaleu B, Satie AP, Patard JJ, Jégou B, Dejucq-Rainsford N (2006) Human testis in organotypic culture: application for basic or clinical research. Hum Reprod 21(6): 1564-1575.

Schlatt S, Honaramooz A, Ehmcke J, Goebell PJ, Rübben H, Dhir R, Dobrinski I, Patrizio P (2006) Limited survival of adult human testicular tissue as ectopic xenograft. Hum Reprod 21(2): 384-389.

Sheikine Y, Genega E, Melamed J, Lee P, Reuter VE, Ye H (2012) Molecular genetics of testicular germ cell tumors. Am J Cancer Res 2(2): 153-167.

Skakkebaek NE, Berthelsen JG, Giwercman A, Müller J (1987) Carcinomain-situ of the testis: possible origin from gonocytes and precursor of all types of germ cell tumours except spermatocytoma. Int J Androl 10(1): 19-28.

Skakkebaek NE, Jensen G, Povlsen CO, Rygaard J (1974) Heterotransplantation of human foetal testicular and ovarian tissue to the mouse mutant nude. A preliminary study. Acta Obstet Gynecol Scand Suppl 29: 73-75.

Sofikitis N, Pappas E, Kawatani A, Baltogiannis D, Loutradis D, Kanakas N, Giannakis D, Dimitriadis F, Tsoukanelis K, Georgiou I, Makrydimas G, Mio Y, Tarlatzis V, Melekos M, Miyagawa I (2005) Efforts to create an artificial testis: culture systems of male germ cells under biochemical conditions resembling the seminiferous tubular biochemical environment. Hum Reprod Update 11(3): 229-259.

Sonne SB, Herlihy AS, Hoei-Hansen CE, Nielsen JE, Almstrup K, Skakkebaek NE, Marks A, Leffers H, Rajpert-De Meyts E (2006) Identity of M2A (D2-40) antigen and gp36 (Aggrus, T1A-2, podoplanin) in human developing testis, testicular carcinoma in situ and germ-cell tumours. Virchows Arch 449(2): 200-206.

Staub C (2001) A century of research on mammalian male germ cell meiotic differentiation in vitro. J Androl 22(6): 911-926.

Steinberger A (1975) In vitro techniques for the study of spermatogenesis. Methods Enzymol 39: 283-296.

Szczepny A, Hogarth CA, Young J, Loveland KL (2009) Identification of Hedgehog signaling outcomes in mouse testis development using a hanging drop-culture system. Biol Reprod 80(2): 258-263.

Young JC, Jaiprakash A, Mithraprabhu S, Itman C, Kitazawa R, Looijenga LH, Loveland KL (2011) TCam-2 seminoma cell line exhibits characteristic foetal germ cell responses to TGF-beta ligands and retinoic acid. Int $J$ Androl 34(4 Pt 2): e204-e217.

Yu J, Cai ZM, Wan HJ, Zhang FT, Ye J, Fang JZ, Gui YT, Ye JX (2006) Development of neonatal mouse and fetal human testicular tissue as ectopic grafts in immunodeficient mice. Asian J Androl 8(4): 393-403.

Wyns C, Curaba M, Martinez-Madrid B, Van Langendonckt A, FrançoisXavier W, Donnez J (2007) Spermatogonial survival after cryopreservation and short-term orthotopic immature human cryptorchid testicular tissue grafting to immunodeficient mice. Hum Reprod 22(6): 1603-1611.

Wyns C, Van Langendonckt A, Wese FX, Donnez J, Curaba M (2008) Long-term spermatogonial survival in cryopreserved and xenografted immature human testicular tissue. Hum Reprod 23(11): 2402-2414.

This work is published under the standard license to publish agreement. After 12 months the work will become freely available and the license terms will switch to a Creative Commons AttributionNonCommercial-Share Alike 3.0 Unported License.

Supplementary Information accompanies this paper on British Journal of Cancer website (http://www.nature.com/bjc) 